\section{Implantation of a New Access Device for Hemodialysis (Dialock): Initial Experience in 5 Patients}

\begin{abstract}
Implantation of a New Access Device for Hemodialysis (Dialock): Initial Experience in 5 Patients. Purpose: A new hemodialysis access port system was implanted. Methods: The Dialock $^{\mathrm{TM}}$ consists of a port-like double-valve, implanted subcutaneously below the clavicle, which is attached to two catheters, placed in the right atrium via the jugular vein. The device has been implanted in 5 patients ( 4 female, 1 male). Results: In all 5 patients the implantation of the catheters and the port was technically successful. Total average duration of dialysis was 3.6 months. Two patients developed a port pocket hematoma 10-14 days post implantation, one of them required surgical revision. One port was explanted due to septicemia, whereas a port infection was not confirmed. One patient showed a thrombotic occlusion of both catheter tips 8 days after implantation, fixed by catheter exchange. Another patient presented with slight migration of the port catheters, which was managed by refixation of the port within the pocket. Beside these complications, the devices were working well. Conclusion: The Dialock system offers an interesting alternative to external catheters for hemodialysis. With respect to the complications it deserves further studies to determine its future role in the field of vascular access.
\end{abstract}

Key words: Hemodialysis - Vascular access - Dialysis access Catheter - Port

Implantierung einer neuen Zugangsvorrichtung zur Hämodialyse (Dialock) - Erste Erfahrungen mit 5 Patienten. Zielsetzung: Ein neues Hämodialyse-Portsystem wurde klinisch erprobt. Methoden: Das Dialock ${ }^{\mathrm{TM}}$-System besteht aus einem Doppelventil-Port, der subkutan unterhalb der Klavikel implantiert wird. An den Port sind zwei Katheter angeschlossen, die subkutan getunnelt transjugulär im rechten Vorhof platziert werden. Das System wurde in 5 Patienten implantiert (4 Frauen, 1 Mann). Ergebnisse: Bei allen 5 Patienten war die Katheter- und Portimplantation technisch erfolgreich. Die bisherige mittlere Dialyse-Dauer beträgt 3,6 Monate. Bei zwei Patienten bildete sich ein Hämatom der Porttasche 10-14 Tage nach der Implantation. In einem Fall war eine operative Ausräumung erforderlich. Ein Patient entwickelte eine Sepsis, worauf das Portsystem explantiert wurde. Eine Portinfektion ließ sich jedoch nicht bestätigen. Ein Patient zeigte einen thrombotischen Verschluss beider Katheter 8 Tage nach Implantation,

Fortschr Röntgenstr 2001; 173: 494-496

(C) Georg Thieme Verlag Stuttgart · New York

ISSN 1438 - 9029
T. Schmitz-Rode ${ }^{1}$, A. Bücker ${ }^{1}$, J. Tacke ${ }^{1}$, M. Wingen ${ }^{1}$, M. Noah', M. Ketteler ${ }^{3}$, R. W. Günther

${ }^{1}$ Department of Diagnostic Radiology

2 Department of Plastic Surgery

${ }^{3}$ Department of Nephrology

Universitätsklinikum der RWTH Aachen

worauf die Katheter ausgetauscht wurden. Ein weiterer Patient zeigte eine Migration der Portkatheter, die durch Refixation des Port behoben wurde. Bis auf die aufgeführten Komplikation arbeiteten alle Portsysteme regelrecht. Schlussfolgerung: Das Dialock-System stellt ein interessante Alternative zu externen Dialyse-Kathetern dar. Im Hinblick auf die aufgetretenen Komplikationen erscheinen weitere Studien notwendig, um den zukünftigen Stellenwert dieses Verfahrens zu ermitteln.

Schlüsselwörter: Hämodialyse - Gefäßzugang - Dialyse-Katheter - Portsystem

\section{Introduction}

Ten to $20 \%$ of hemodialysis patients are dependent on external catheters as a permanent access [1]. These include patients who have no other access sites available due to prior fistulas or poor vascular anatomy, and those awaiting the maturation of a newly created arteriovenous fistula or healing of a freshly implanted polytetrafluoroethylene graft. External catheters have a high failure rate due to thrombosis and infection $[2,3]$. They usually do not offer a favorable prognosis for more than 12 months. We describe our first experiences with a new fully implantable hemodialysis access port system, connected to two catheters, which may serve as an alternative to external catheters in this group of patients.

\section{Materials and Methods}

\section{Hemodialysis access device}

The system (Dialock ${ }^{\mathrm{TM}}$, Biolink Corp., Middleboro, MA, USA) consists of two $11 \mathrm{~F}$ silicone catheters connected to a titanium port with the dimensions $5 \times 2.5 \times 1.25 \mathrm{~cm}$. The port has a double needle passage to be punctured percutaneously by two specially designed needle-cannulas. A valve assembly within the port prevents leakage and automatically closes when the needles are withdrawn. After the dialysis session an antithrombotic lock with heparin is instilled to prevent clotting of the catheters. The CE-marked and FDA-approved system is available as a set (A. Schulz-Lauterbach, Iserlohn, Germany).

\section{Implantation procedure}

All devices were implanted in an angiographic suite by an interventional radiologist, in cooperation with a surgeon (who prepared the port pocket). First, the jugular vein was localized 


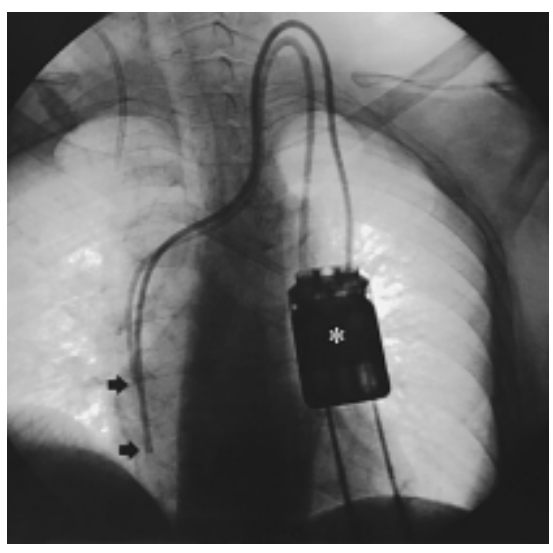

Fig. 1 Chest X-ray after implantation of the hemodialysis access device: * subcutaneous port below the left clavicle, punctured from below by two hemodialysis cannulas. $\rightarrow$ Tips of the catheters at different levels in the right atrium (Shaldon catheter in the right subclavian vein).

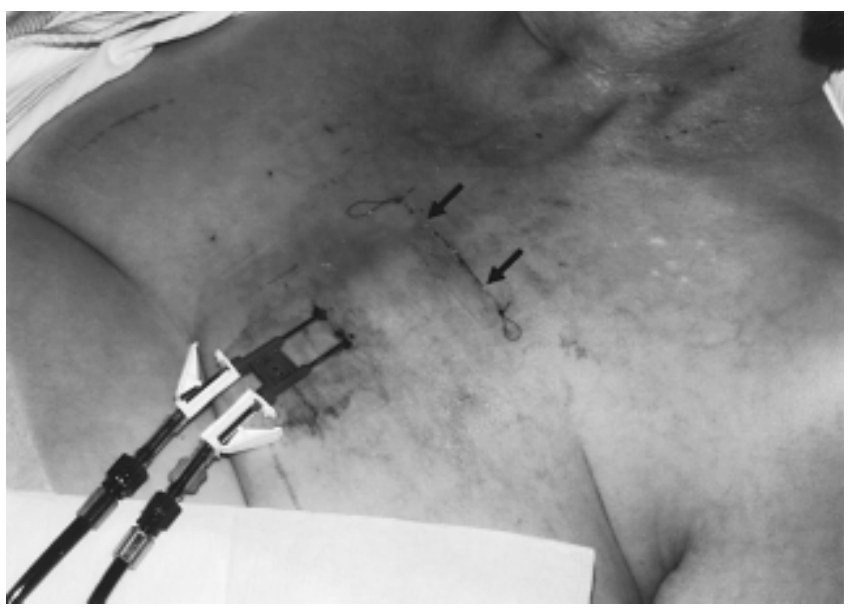

Fig. 2 Dialock port system in use for hemodialysis (1 week after implantation): Port system punctured by twin needle-cannulas. $\rightarrow$ Suture of the port pocket.

using ultrasound. Preferrably the right side was chosen for access. In two cases with occlusion or high-grade stenosis of the right brachiocephalic vein the left jugular vein was accessed. After local anesthesia (Meaverin, Mepivacainhydrochlorid 1\%, Rhone-Poulenc-Rorer GmbH, Köln, Germany) and double puncture of the vein the two catheters were inserted through a peel-away sheath. The catheter tips were placed at different levels in the right atrium under fluoroscopic control. For implantation of the port local anesthetics (Meaverin) were distributed spaciously into the subcutaneous tissue of the anterior chest wall a few centimeters below the clavicle. After a transverse incision of $6 \mathrm{~cm}$ length a pocket was prepared. The catheters were tunneled from the venous accesss site to the port pocket and connected to the port. After fixation of the port to the pectoral fascia the pocket was closed by suture.

\section{Patients}

The Dialock port system was implanted in 4 female and one male patients (average age of 59 years). All of our patients had external central venous catheters with infectious complications and inadequate veins to create a new native or prosthetic fistula after a history of failed fistulas and/or grafts. Dialock implantation was considered as an ultimate option of treatment.

The indication was hemodialysis access in 4 patients with chronic renal failure and plasmapheresis in one patient with myasthenia. All implants were performed under local anesthesia. All patients received prophylactic systemic antibiotics $(2 \mathrm{~g}$ Spizef i.v., Cefotiam, Takeda, Aachen, Germany) two hours before implantation.

\section{Results}

In all 5 patients the implantation of the catheters and the port was technically successful. Healing of the implant was uneventful. There was no implant or puncture site infection.

The total average duration of dialysis with the port system was 3.6 months at the time of report writing.

One patient has been undergoing weekly plasmapheresis for now more than half a year without complication. The four hemodialysis patients underwent dialysis three times a week.

One of the dialysis patients developed a hematoma at the port site 14 days after implantation, which required surgical revision. After this reintervention the system has been working now for more than half a year without complications.

Another dialysis patient developed a moderate hematoma 10 days after implantation, without the need for treatment. After three months she was readmitted with signs of septicsemia, which gave reason to explant the port. However, a port infection was not confirmed.

The third dialysis patient showed a thrombotic occlusion of both catheter tips 8 days after implantation. Catheter cleaning via access port using different guide wires and a stripping maneuver of the fibrin sheaths covering both outer catheter tips by a transfemoral snare did not prevent reocclusion. The port pocket was reopened to exchange the catheters. This revealed a tear in one of the catheters close to the port connector. After catheter exchange and a coumarin therapy the system is working well up to date.

The fourth dialysis patient showed migration of the catheter tips from the right atrium to the orifice of the inferior vena cava within one week after implantation, due to cranial migration of the port within the pocket. Obviously, this was provoked by needle puncturing the port from below for dialysis access without fixing it by palpation. Surgical revision of the port pocket with thorough refixation of the port more caudally solved this problem.

\section{Discussion}

The Dialock system represents a new approach in vascular access for hemodialysis and plasmapheresis in patients who have no viable vascular site for creation of a fistula. It is a modification of the vascular access port used for chemotherapy [4].

Due to the novelty of the system there are only limited data available in the literature [5 - 7], comprising a US and French 
pilot study including 23 patients. According to this study the device was well accepted by patients and staff. Dialysis adequacy was achieved in all cases, with an effective blood flow rate $>300 \mathrm{ml} / \mathrm{min}$. The complications reported are very similar to the ones encoutered in our small group of patients.

Hematoma surrounding the Dialock device was observed in $7.2 \%$ of the cases [7]. All hematomas occured in the initial phase of dialysis with the system. In one case a surgical revision was necessary. The cause of hematomas of the port pocket was explained as spilling out of the heparin lock from the distal holes during the interdialytic period and was managed by reduction of the heparin dose [7].

The study reports 11 infections in 23 patients [5-8]. All were revealed as bacteremia, not as an infection of the device. Related to the number of implant days this was equal to 2.5 bacteremias per 1000 patient days, comparing favorably with that of standard permanent catheters (up to 5.1) [8]. According to this and another study [9], the successful therapy consisted of a catheter lock of heparin and antibiotics between the dialysis sessions, combined with systemic antibiotic therapy. In none of the cases was there a need to remove the device. According to these data the explantation of one system in our group of patients could probably have been avoided. However, Megerman et al. [8] did not describe strategy and outcome of one pocket infection.

Two devices were explanted because of thrombotic material around catheter tips, in order to rule out infection [6]. In two further patients stripping of fibrin sheaths was performed to recanalize the catheters [10]. In one of the cases the second repetition of this procedure, together with a urokinase lock of the catheters and a systemical urokinase therapy led to a correction of the problem. We managed this problem in our patient by exchange of the catheters. A leakage of one of the exchanged catheters might be due to manipulation in the previous stripping maneuver.

\section{Conclusion}

The Dialock system offers a new concept and an interesting alternative to external catheters in the vascular access strategy for hemodialysis and plasmapheresis. With regard to the number of problems and complications encoutered in our small group of patients as well as in the US/French pilot study, it requires further studies to determine the place of this device in the field of vascular access.

\section{Literatur}

${ }^{1}$ Suhocki PV, Conlon PJ, Knelson MH, Harland R, Schab SJ. Silastic cuffed catheters for hemodialysis vascular access: Thrombolytic and mechanical correction of malfunction. Am J Kidney Dis 1996; 28: $379-386$

${ }^{2}$ Feldman HI, Kobrin S, Wasserstein A. Hemodialysis vascular access morbidity. J Am Soc Nephrol 1996; 7: 523-535

${ }^{3}$ Tesio F, De Baz H, Panarello G, Calianno G, Quaia P, Raimondi A, Schinella D. Double catheterization of the internal jugular vein for hemodialysis: indications, techniques, and clinical results. Artif Organs 1994; 18: $301-304$
${ }^{4}$ Brothers TE, Von Moll LK, Niederhuber JE, Roberts JA, WalkerAndrews S, Ensminger WD. Experience with subcutaneous infusion ports in three hundred patients. Surg Gynecol Obstet 1988; 166: 295 - 301

${ }^{5}$ Levin NW, Yang PM, Hatch DA, Dubrow AJ, Caraiani NS, Ing TS, Gandhi VC, Alto A, Davila SM, Prosl FR, Polaschegg HD, Megerman J. New access device for hemodialysis. ASAIO J 1998; 44(5): M529-M531

${ }^{6}$ Levin NW, Yang PM, Hatch DA, Dubrow AJ, Craiani NS, Ing TS, Gandhi VC, Alto A, Davila SM, Prosl FR, Polaschegg HD, Megerman $\mathrm{J}$. Initial results of a new access device for hemodialysis: technical note. Kidney International 1998; 54(5): 1739-1745

${ }^{7}$ Canaud B, My H, Morena M, Lamy-Lacavalerie B, Leray-Moragues H, Bosc JY, Flavier JL, Chomel PY, Polaschegg HD, Prosl FR, Megerman J. Dialock: a new vascular access device for extracorporeal renal replacement therapy. Preliminary clinical results. Nephrol Dial Transplant 1999; 14(3): 692 -698

${ }^{8}$ Megerman J, Levin NW, Ing TS, Dubrow AJ, Prosl FR. Development of a new approach to vascular access. Artif Organs 1999; 23(1): $10-14$

${ }^{9}$ Boorgu R, Dubrow AJ, Levin NW, My H, Canaud BJ, Lentino JR, Wentworth DW, Hatch DA, Megerman J, Prosl FR, Gandhi VC, Ing TS. Adjunctive antibiotic/anticoagulant lock therapy in the treatment of bacteremia associated with the use of a subcutaneously implanted hemodialysis access device. ASAIO J 2000; 46(6): $767-770$

${ }^{10}$ Crain MR, Mewissen MW, Ostrowski GJ, Paz-Fumagalli R, Berez RA, Wertz RA. Fibrin sleeve striping for salvage of failing hemodialysis catheters. Radiology 1996; 198: $41-44$

Prof. Dr. med. Dipl.-Ing. Thomas Schmitz-Rode

Klinik für Radiologische Diagnostik

Universitätsklinikum der RWTH Aachen

Pauwelsstraße 30

52057 Aachen

Tel. + 49-241-8088332

Fax + 49-241-8888480

E-mail: smiro@rad.rwth-aachen.de 